\title{
TRATAMENTO DE SEMENTES DE SOJA COM ZINCO: EFEITO NA QUALIDADE FISIOLÓGICA E PRODUTIVIDADE
}

Elisa Souza Lemes ${ }^{1}$, André Oliveira de Mendonça ${ }^{2}$, Leticia Winke Dias ${ }^{1}$, André Pich Brunes ${ }^{3}$, Sandro de Oliveira ${ }^{1}$, Silvana Spaniol Fin ${ }^{1}$, Geri Eduardo Meneghello ${ }^{1}$

${ }^{1}$ Universidade Federal de Pelotas- UFPel, Faculdade de Agronomia Eliseu Maciel - FAEM, Pelotas, RS. ${ }^{2}$ Instituto Federal de Educação Ciência e Tecnologia Farroupilha- Campus Alegrete, Alegrete, RS. ${ }^{3}$ Universidade Federal do Rio Grande do Sul-UFRGS, Porto Alegre, RS. E-mail: lemes.elisa@yahoo.com.br

\section{RESUMO}

O objetivo deste trabalho foi avaliar o efeito do tratamento de sementes de soja com zinco na qualidade fisiológica das sementes tratadas e nas características agronômicas. $O$ delineamento experimental adotado foi inteiramente casualizado, em esquema fatorial $2 \times 5$ (Lotes: A e B; e doses da fonte: $0,2,4,6$ e $8 \mathrm{~mL} \mathrm{~kg}^{-1}$ de semente). Após o tratamento das sementes, foi analisada a qualidade fisiológica das mesmas, avaliadas pelo teste de germinação, primeira contagem de germinação, teste frio, envelhecimento acelerado, comprimento da parte aérea e de raiz. Na sequência foi realizada a semeadura das sementes tratadas em vasos, conduzindo o experimento até a fase de maturação de campo. Após a colheita, foram avaliadas as características agronômicas e a qualidade fisiológica das sementes produzidas. As características agronômicas foram avaliadas através do número de sementes por planta, número de legumes por planta, peso de sementes por planta. A qualidade das sementes produzidas foi avaliada pelos testes acima citados mais o teste de emergência a campo. $O$ tratamento das sementes de soja nas doses entre 2 a $6 \mathrm{~mL} k \mathrm{~kg}$ de sementes $^{-1}$ apresentou os melhores resultados para a qualidade fisiológica e características agronômicas. 0 número de sementes por planta, número de legumes por planta e peso de sementes por planta apresentam incrementos com o aumento das doses de zinco. O tratamento das sementes de soja com zinco não influencia a qualidade fisiológica das sementes produzidas. Os lotes apresentam comportamentos diferentes em resposta ao tratamento das sementes com zinco.

Palavras-Chave: Glycine $\max$ (L.), micronutriente, viabilidade, vigor, recobrimento.

\section{SOYBEAN SEED TREATMENT WITH ZINC: EFFECT ON PHYSIOLOGICAL SEED QUALITY AND CROP YIELD}

\begin{abstract}
The study aimed to evaluate the effect of seed treatment of soybean with zinc in physiological quality of treated seed produced and the agronomic characteristics. The experimental design was completely randomized, factorial $2 \times 5$ (Lots: $A$ and $B$, and the zinc source doses: $0,2,4,6$ and $8 \mathrm{ml} \mathrm{kg}^{-1}$ seed). After seed treatment, the physiological quality was assessed by germination, first germination count, cold test, accelerated aging, shoot and root length. After harvest, the agronomic characteristics and physiological seed quality were evaluated. For the agronomic traits, the number of seeds per plant, number of pods per plant and seed weight per plant were evaluated. For the produced seed quality, the same tests aforementioned was evaluated plus the emergency field test. The treatment of soybean seeds in doses ranged from 2 to $6 \mathrm{ml} \mathrm{kg}^{-1}$ seeds showed the best results for the physiological seed quality and agronomic characteristics. The number of seeds per plant, number of pods per plant and seed weight per plant have increments with increasing doses of zinc. The seed treatment with zinc does not influence the physiological produced seed quality. The lots show different behaviors in response to seed treatment with zinc.
\end{abstract}

Keywords: Glycine max (L.), micronutrient, viability, vigor, coating. 


\section{INTRODUÇÃO}

A soja (Glycine max (L.) Merrill) possui importância incontestável no cenário agrícola mundial, com produção de mais de 351 milhões de toneladas (USDA, 2017). No contexto nacional a importância é ainda maior, uma vez que se constitui no principal produto agrícola de exportação, sendo responsável por grande parte do agronegócio no país, ocupando mais de $50 \%$ da área total, correspondendo a mais de 33 milhões de hectares semeados, sendo previsto uma produção de mais de 113 milhões de toneladas (CONAB, 2017).

Altas produtividades são obtidas com o uso de modernas práticas de cultivos e adoção de novas tecnologias que visam maior produtividade a fim de atender à crescente demanda do mercado por essa importante commodity. A utilização de produtos e nutrientes que auxiliam o desempenho das sementes no campo é uma prática que vem tornando-se rotineira, contribuindo para o aumento do potencial produtivo. De acordo com Carvalho e Nakagawa (2000), a produtividade de sementes e a qualidade fisiológica das mesmas são diretamente dependentes da disponibilidade de nutrientes na lavoura. Desta forma a adubação merece especial atenção, pois a falta de micronutrientes como o zinco (Zn), pode acarretar em sérios prejuízos, como a redução da taxa de crescimento vegetal, impedimento da expansão das folhas, o alongamento do caule e restrição do crescimento das raízes (BERGMANN, 1992) e consequentemente redução da produtividade.

O zinco é um micronutriente de importância tanto para as plantas quanto para o ser humano. Participa em diversos processos nos vegetais, dentre eles a fotossíntese, respiração, controle hormonal, síntese de aminoácidos e de proteínas, redução do nitrato e desintoxicação de radicais livres (MALAVOLTA, 2006; MARSCHNER, 2012). Este elemento é um importante ativador e constituinte de enzimas nas plantas, dentre as quais estão a anidrase carbônica, desidrogenase alcoólica, superóxido dismutase (CuZnSOD), aldolase, sintetase do triptofano, entre outras. Esta última é responsável pela produção de ácido indolacético (AIA) nos vegetais, crucial para o crescimento apical e expansão celular (EPSTEIN; BLOOM, 2004).

As doses de zinco requeridas pelas culturas são pequenas (FURLANI, 1996), existindo assim dificuldade em distribuir uniformemente os adubos na aplicação via solo (RIBEIRO; SANTOS, 1996), restando como alternativa a aplicação foliar, no entanto, as pulverizações apresentam como desvantagem a baixa mobilidade do zinco no floema (LONGNECKER; ROBSON, 1993). A baixa eficiência do uso pelas plantas se deve principalmente pela má distribuição dos elementos na cultura, reações no solo que os tornam indisponíveis para as plantas e a baixa mobilidade dos mesmos no solo, especialmente para os micronutrientes (MARSCHNER, 2012). Com isso, são necessárias ferramentas de manejo que aumentem a precisão da distribuição dos nutrientes no campo e aproximem os mesmos da zona de absorção da raiz. Desta forma, o fornecimento via tratamento de sementes apresenta menores custos de aplicação, melhor uniformidade na distribuição, redução das perdas, além da racionalização no uso de reservas naturais não renováveis (BONNECARRÉRE et al., 2003), podendo ser uma alternativa eficiente para a garantia de quantidades adequadas para o desenvolvimento das culturas.

O zinco apresenta uma eficácia sobre a germinação das sementes através de alterações bioquímicas na germinação, destacando-se como elemento acelerador do crescimento da radícula. De acordo com SINGH (2007) o tratamento de sementes com zinco, com doses variando de 6 a $10 \mathrm{~mL} \mathrm{~kg}^{-1}$ de sementes, melhorou o desempenho das culturas do milho, trigo, soja, girassol, amendoim e mostarda. Do mesmo modo foi observado por MOREIRA et al. (2011) trabalhando com sementes de trigo, no qual observou que o tratamento com dois produtos a base de nutrientes na dose de $2 \mathrm{~mL} \mathrm{~kg}^{-1}$ de sementes proporcionou melhores resultados para número de espigas por metro, altura de planta, comprimento de raiz e produtividade.

Em vista disso, o presente trabalho objetivou verificar o efeito do tratamento de sementes de soja com zinco na qualidade fisiológica das sementes tratadas e produzidas bem como nos componentes do rendimento.

\section{MATERIAL E MÉTODOS}

O trabalho foi conduzido no Laboratório Didático de Análise de Sementes (LDAS) e em casa de vegetação, pertencentes à Faculdade de Agronomia Eliseu Maciel, da Universidade Federal de Pelotas. Foram utilizados dois lotes de sementes de soja da cultivar V-Max RR. 
O delineamento experimental utilizado foi inteiramente casualizado, em esquema fatorial 2 $X 5$ (Lotes: A e B; e doses da fonte: 0, 2, 4, 6 e 8 $\mathrm{mL} \mathrm{kg^{-1 }}$ de semente) com quatro repetições. Como fonte de zinco foi utilizado o produto comercial Quimifol Seed $78^{\circ}$, o qual contém $780 \mathrm{~g}$ $\mathrm{L}^{-1}$ de zinco. $\mathrm{O}$ tratamento das sementes foi realizado em sacos de polietileno, segundo procedimento descrito por Nunes (2005), onde foram depositadas no fundo de cada saco as doses de zinco, juntamente com água para completar o volume de calda, sendo mantido o volume de $8 \mathrm{~mL} \mathrm{~kg}^{-1}$ de semente para todos os tratamentos. Posteriormente, em cada saco foi colocado $0,100 \mathrm{~kg}$ de sementes, as quais foram agitadas por 3 minutos, após esse período as mesmas foram postas para secar a temperatura ambiente durante 24 horas.

Após o tratamento, foi analisada a qualidade fisiológica das sementes, avaliada pelos testes de germinação $(G)$ e vigor, considerandose primeira contagem de germinação (PCG), teste frio (TF), envelhecimento acelerado (EA), comprimento da parte aérea (CPA) e de raiz (CR), conforme metodologias descritas posteriormente.

Na sequência foi realizada a semeadura das sementes em vasos, com capacidade de 8 litros, os quais foram preenchidos com solo peneirado, coletado de um horizonte A1 de um PLANOSSOLO HÁPLICO Eutrófico solódico (STRECK et al., 2008), pertencente à unidade de mapeamento Pelotas. Em cada vaso foram semeadas dez sementes, com posterior desbaste, permanecendo três plantas por vaso, conduzindo o experimento até a fase de maturação de campo. A adubação foi realizada de acordo com os resultados da análise de solo e recomendações da Comissão de Química e Fertilidade do Solo $\mathrm{RS} / \mathrm{SC}$ (2016). A calagem foi realizada trinta dias antes da semeadura e a adubação com nitrogênio, fósforo e potássio ocorreu 14 dias antes da semeadura.

Após a colheita, foram avaliadas as características agronômicas e a qualidade fisiológica das sementes produzidas. Os componentes do rendimento foram avaliados através da contagem direta do número de legumes por planta (NLPL), número de sementes por planta (NSPL), peso de sementes por planta (PSPL), que foi obtido pela pesagem das sementes colhidas, sendo a umidade das sementes corrigida para $13 \%$. Os resultados foram expressos em $g$ planta ${ }^{-1}$.
$\mathrm{Na}$ sequência foram realizadas avaliações da qualidade das sementes produzidas através dos testes de: Germinação - realizado de acordo com as Regras para Análise de Sementes RAS (BRASIL, 2009), por meio da semeadura de 200 sementes, divididas em quatro repetições de 50 sementes, em rolo de papel tipo germitest umedecido, previamente, com água destilada na proporção de 2,5 vezes o peso do papel seco. Os rolos foram colocados em germinador à temperatura de $25 \circ \mathrm{C}$, a contagem foi realizada aos 8 dias após a semeadura, sendo os resultados expressos em porcentagem de plântulas normais. Primeira contagem da germinação - realizado conjuntamente ao teste de germinação, sendo a contagem de plântulas normais executada aos 5 dias após a semeadura e os resultados expressos em porcentagem de plântulas normais. Teste de frio - conduzido com quatro subamostras de 50 sementes para cada repetição, distribuídas uniformemente em rolo de papel tipo germitest umedecido, previamente, com água destilada na proporção de 2,5 vezes o peso do papel seco. Em seguida os rolos de papel foram colocados em sacos plásticos, os quais foram vedados e mantidos em câmara de $B O D$, regulada à temperatura de $10 \pm 1$ 으 durante sete dias. Após esse período, os rolos foram retirados dos sacos plásticos e transferidos para um germinador e mantidas nas mesmas condições do teste de germinação, sendo avaliada a porcentagem de plântulas normais após 5 dias (CÍCERO; VIEIRA, 1994). Envelhecimento acelerado - as sementes foram espalhadas em camada única sobre uma tela metálica suspensa dentro de caixas de gerbox, contendo $40 \mathrm{~mL}$ de água destilada ao fundo. Posteriormente as caixas foram tampadas e acomodadas em câmara BOD, a 41 으 por $48 \mathrm{~h}$ (MARCOS FILHO, 2005). Após este período as sementes foram colocadas para germinar conforme metodologia descrita para o teste de germinação, e avaliadas no quinto dia, sendo os resultados expressos em porcentagem de plântulas normais. Comprimento de plântula realizado com quatro subamostras de 20 sementes para cada repetição, que foram dispostas alinhadas na parte superior do papel de germinação tipo germitest, umedecido a 2,5 vezes o seu peso seco. Os rolos foram acondicionados em germinador a 25으. A leitura foi realizada aos cinco dias após a semeadura, com auxílio de régua graduada em milímetros, sendo medido o comprimento total e o comprimento da parte aérea de dez plântulas 
normais. O comprimento da raiz foi determinado pela subtração do comprimento total pelo comprimento da parte aérea. Os comprimentos médios da parte aérea e da raiz foram determinados somando-se as medidas de cada repetição e dividindo pelo número de plântulas avaliado, conforme metodologia descrita por (NAKAGAWA, 1999). Emergência a campo (EC) para esta determinação foram semeadas 200 sementes, distribuídas em 4 repetições de 50 sementes para cada tratamento, sendo a semeadura realizada em canteiros. A avaliação foi realizada em contagem única das plântulas normais aos 21 dias após a semeadura, sendo os resultados expressos em percentagem, (NAKAGAWA, 1999).

Os dados do experimento foram submetidos à análise de variância e havendo significância, realizou-se comparação de médias através do teste de Tukey para o fator cultivar e regressão polinomial para o fator dose da fonte, todos a $5 \%$ de probabilidade.

\section{RESULTADOS E DISCUSSÃO}

Para a primeira contagem da germinação observou-se que não houve interação entre os fatores cultivar e doses de zinco, porém manifestou-se o efeito principal dos fatores testados, sendo então realizado comparação de médias para o fator lote e regressão polinomial para o fator dose. Nesta variável verificou-se que o Lote B foi superior ao Lote A (Tabela 1). Nas variáveis germinação, teste de frio, envelhecimento acelerado, comprimento da parte aérea e comprimento de raiz foi constatado interação entre os fatores. Para a germinação o Lote $B$ foi superior ao Lote $A$ nas doses de 2 e 4 $\mathrm{mL} \mathrm{kg} \mathrm{de} \mathrm{sementes}{ }^{-1}$. Para o teste de frio o mesmo lote respondeu melhor ao tratamento nas doses de 0,2 e $4 \mathrm{~mL} \mathrm{~kg} \mathrm{de} \mathrm{sementes}{ }^{-1}$. No entanto, para o envelhecimento acelerado o Lote A foi superior na dose de $6 \mathrm{~mL} \mathrm{~kg}$ de sementes ${ }^{-1}$.

Nas demais variáveis (CPA e CR) o Lote $A$ foi superior ao Lote $B$ em todas as doses testadas. Essa diferença de resposta entre os dois lotes de soja em função do tratamento das sementes com as doses de zinco, pode ser explicada pela existência de diferença genética entre elas. Além disso, dentre os fatores que podem influenciar a absorção de Zn, destaca-se a cultivar utilizada (FURLANI et al., 2005), as características físicoquímicas da solução do solo (ALLOWAY, 2008) e clima. Os resultados obtidos, demonstram que existe uma grande variação de resposta entre lotes da mesma cultivar quando submetidos ao tratamento de sementes. 
Tabela 1. Porcentagem de plântulas normais obtidas nos testes de primeira contagem da germinação (PCG), germinação (G), teste de frio (TF), envelhecimento acelerado (EA), comprimento da parte aérea (CPA) e de raiz (CR) de sementes de soja tratadas com diferentes doses de zinco.

\begin{tabular}{|c|c|c|c|c|c|c|}
\hline \multirow{2}{*}{ Dose* } & \multicolumn{2}{|c|}{ PCG (\%) } & \multicolumn{2}{|c|}{ G (\%) } & \multicolumn{2}{|c|}{ TF (\%) } \\
\hline & Lote A & Lote B & Lote A & Lote B & Lote A & Lotes B \\
\hline 0 & 82 & 89 & $88 a$ & $91 \mathrm{a}$ & $77 \mathrm{~b}$ & $84 a$ \\
\hline 2 & 84 & 92 & $89 \mathrm{~b}$ & $95 a$ & $73 \mathrm{~b}$ & $88 \mathrm{a}$ \\
\hline 4 & 86 & 93 & $91 \mathrm{~b}$ & $96 a$ & $71 \mathrm{~b}$ & $82 \mathrm{a}$ \\
\hline 6 & 84 & 91 & $91 \mathrm{a}$ & $89 a$ & $68 \mathrm{a}$ & $68 \mathrm{a}$ \\
\hline 8 & 83 & 85 & $92 \mathrm{a}$ & $87 \mathrm{~b}$ & $67 a$ & $66 a$ \\
\hline Média & $84 \mathrm{~b}$ & $90 a$ & 90 & 91 & 71 & 78 \\
\hline C.V & & & & & & \\
\hline \multirow{2}{*}{ Dose } & \multicolumn{2}{|c|}{ EA (\%) } & \multicolumn{2}{|c|}{$\mathrm{CPA}(\mathrm{cm})$} & \multicolumn{2}{|c|}{$\mathrm{CR}(\mathrm{cm})$} \\
\hline & Lote A & Lote B & Lote A & Lote B & Lote A & Lote B \\
\hline 0 & $85 a$ & $85 a$ & $7,3 \mathrm{a}$ & $5,3 \mathrm{~b}$ & $12,5 \mathrm{a}$ & $8,8 \mathrm{~b}$ \\
\hline 2 & $88 a$ & $89 a$ & $7,4 \mathrm{a}$ & $6,1 \mathrm{~b}$ & $12,5 \mathrm{a}$ & $9,5 \mathrm{~b}$ \\
\hline 4 & $88 a$ & $88 a$ & $7,5 \mathrm{a}$ & $6,4 \mathrm{~b}$ & $12,5 \mathrm{a}$ & $9,6 \mathrm{~b}$ \\
\hline 6 & $85 a$ & $78 \mathrm{~b}$ & $7,5 \mathrm{a}$ & $6,1 \mathrm{~b}$ & $12,5 \mathrm{a}$ & $9,5 b$ \\
\hline 8 & $80 a$ & $77 a$ & $7,8 \mathrm{a}$ & $6,1 \mathrm{~b}$ & $12,4 \mathrm{a}$ & $9,5 b$ \\
\hline Média & 85 & 83 & 7,5 & 6,0 & 12,5 & 9,4 \\
\hline C.V (\%) & \multicolumn{2}{|c|}{2,9} & \multicolumn{2}{|c|}{3,8} & \multicolumn{2}{|c|}{1,2} \\
\hline
\end{tabular}

${ }^{*} \mathrm{~mL} \mathrm{~kg}$ de sementes ${ }^{-1} ;{ }^{* *}$ Médias seguidas pela mesma letra, em cada variável, não diferem entre si pelo teste de Tukey a $5 \%$ de probabilidade.

No que se refere à variável primeira contagem de germinação em função da variação das doses de zinco, constatou-se que o modelo que melhor se ajustou aos dados foi o quadrático em que o ponto de máxima eficiência foi obtido na dose de $3,7 \mathrm{~mL} \mathrm{~kg}$ de sementes ${ }^{-1}$, sendo a porcentagem de plântulas normais de $89 \%$ (Figura 1A). Para a germinação o Lote $A$ apresentou comportamento linear crescente, com um incremento de 0,5 ponto percentual para cada unidade de aumento da dose (Figura 1B). Já o Lote B apresentou comportamento quadrático com ponto de máxima eficiência na dose de $3,1 \mathrm{~mL} \mathrm{~kg}$ de sementes ${ }^{-1}$ (94\% de plântulas normais). Em sementes de aveia tratadas com produtos à base de zinco, Tavares et al. (2013) observaram que a máxima germinação de aveia foi obtida na dose de zinco de $2,8 \mathrm{~mL} \mathrm{~kg}$ de sementes ${ }^{-1}$. No entanto, Funguetto et al. (2010) trabalhando com sementes de arroz revestidas com uma fonte de zinco, fungicida e polímero, também não observaram mudança na germinação, concordando com Tunes et al. (2012) que não observou diferença na germinação em sementes de trigo tratadas com zinco. Segundo Oliveira et al. (2010) a aplicação de micronutrientes em positivamente a qualidade fisiológica das sementes de mamona afeta. 
Figura 1. Primeira contagem da germinação (A), germinação (B), teste de frio (C), envelhecimento acelerado (D), comprimento da parte aérea $(E)$ e de raiz $(F)$ de plântulas de soja tratadas com diferentes doses de zinco.
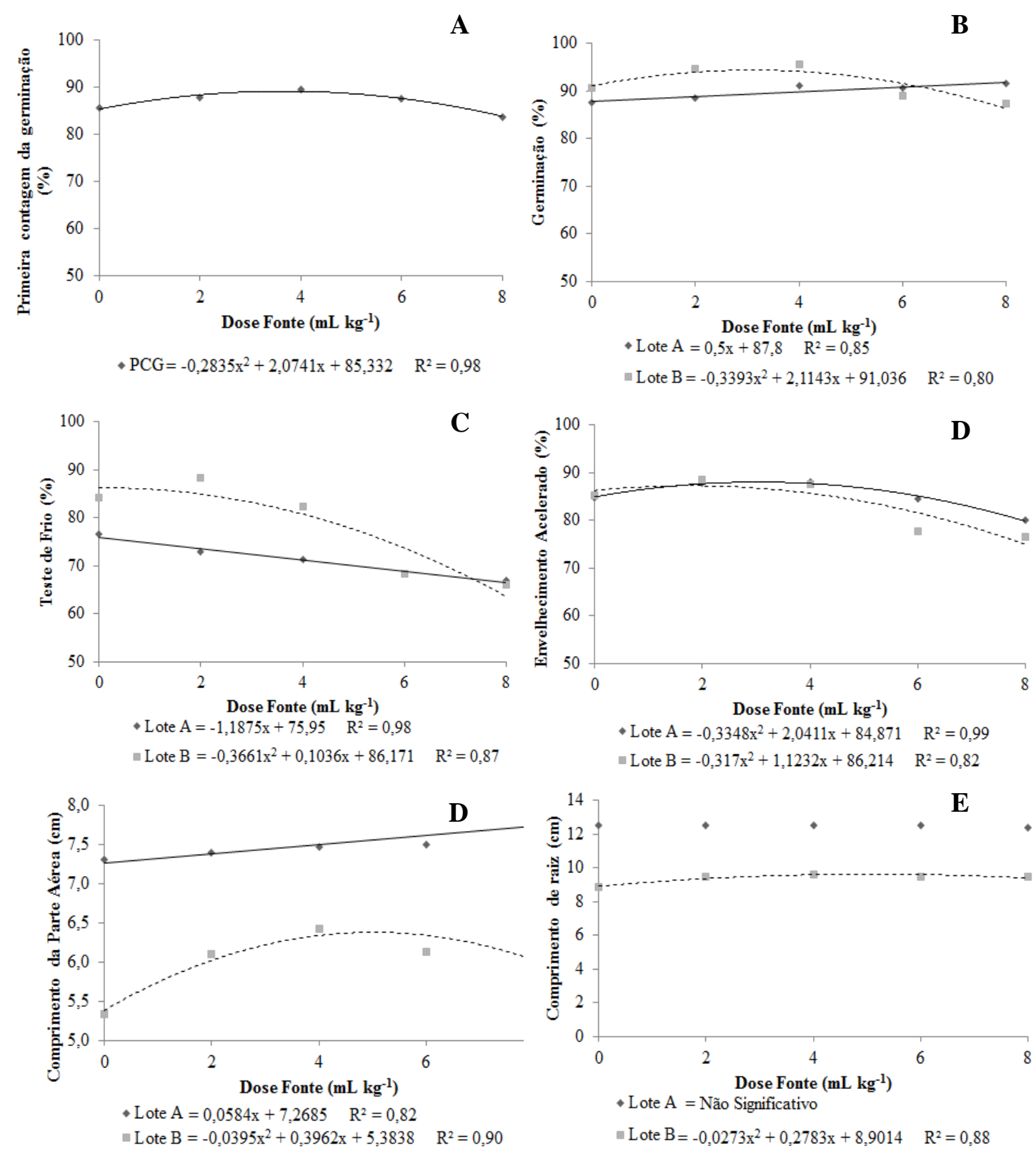

Em relação ao envelhecimento acelerado, observa-se que ambos os lotes apresentaram comportamento quadrático, com aumento na porcentagem de plântulas normais até a dose de $3,1 \mathrm{~mL} \mathrm{~kg}$ de sementes ${ }^{-1}$ para o Lote $A$ e de 1,8 $\mathrm{mL} \mathrm{kg}$ de sementes ${ }^{-1}$ para o Lote B (Figura $1 \mathrm{C}$ ). No teste de frio, o comportamento foi distinto entre os lotes, no Lote $A$ o modelo que se ajustou aos dados foi o linear, com redução de 1,18 pontos percentuais para cada unidade de aumento da dose de zinco aplicada. Já para o Lote $B$ o modelo que se ajustou aos dados foi o quadrático, sendo possível observar que nas doses mais elevadas há uma redução na porcentagem de plântulas normais em baixa

temperatura (Figura 1D). De acordo com Malavolta (2006), o zinco é requerido em pequenas quantidades, apresentando uma estreita faixa entre $o$ efeito benéfico e a toxicidade, o que pode explicar as reduções na porcentagem de plântulas normais com a aplicação de doses mais elevadas de zinco. Semelhantemente, em trabalho com sementes de sorgo tratadas com cinco doses de zinco, foram observados acréscimos com subsequente queda nos percentuais de germinação (YAGl et al., 2006).

No comprimento da parte aérea, o Lote $A$ apresentou comportamento linear com incremento de $0,06 \mathrm{~cm}$, sendo que na maior dose 
aplicada ( $8 \mathrm{~mL} \mathrm{~kg} \mathrm{de} \mathrm{sementes}{ }^{-1}$ ) esse incremento resultou num comprimento de $7,74 \mathrm{~cm}$ (Figura 1 E). Já o Lote B apresentou comportamento quadrático com ponto de máxima eficiência na dose de $5 \mathrm{~mL} \mathrm{~kg}$ de sementes ${ }^{-1}$, reduzindo essa variável em doses mais elevadas. Esse decréscimo em doses mais elevadas também foi observado por Assis et al. (2012) em sementes de coentro tratadas com fertilizantes a base de zinco e molibdênio. Para o comprimento de raiz (Figura 1 F) não foi observado diferença entre os tratamentos para o Lote $A$, já o Lote $B$ atingiu o ponto de máxima eficiência na dose de $5,1 \mathrm{~mL} \mathrm{~kg}$ de sementes ${ }^{-1}(9,6 \mathrm{~cm})$. Como o zinco tem como função promover o crescimento, esse incremento no crescimento das plântulas, deve-se ao fato do zinco exercer importantes funções no metabolismo das plantas, participando da síntese do aminoácido triptofano, precursor do AIA (Ácido Indol Acético) que é o principal hormônio promotor do crescimento, além de ativar várias enzimas e ser componente estrutural de outras (EPSTEIN; BLOOM, 2004).

Os componentes do rendimento das plantas produzidas de sementes tratadas com diferentes doses de zinco mostraram interação entre o fator lote e o fator dose para as variáveis número de sementes por planta, número de legumes por planta e peso de sementes por planta (Tabela 2). Para o número de sementes por planta, contatou-se que nas doses de 4,6 e 8 $\mathrm{mL} \mathrm{kg}$ de sementes ${ }^{-1}$ o Lote $A$ foi superior ao Lote B. Para o número de legumes por planta foi constatado diferença apenas na dose de $8 \mathrm{~mL} \mathrm{~kg}$ de sementes ${ }^{-1}$, onde o Lote A foi superior ao Lote B. Em relação ao peso de sementes por planta o Lote $A$ nas doses de 0 e $8 \mathrm{~mL} \mathrm{~kg}$ de sementes ${ }^{-1}$ foi superior.

Tabela 2. Número de sementes por planta (NSPL), número de legumes por planta (NLPL) e peso de sementes por planta (PSPL) oriundas de sementes de soja tratadas com diferentes doses de zinco.

\begin{tabular}{ccccccc}
\hline \multirow{2}{*}{$\begin{array}{c}\text { Dose } \\
(\mathrm{mL} \mathrm{kg} \mathrm{de} \mathrm{sementes}\end{array}$} & \multicolumn{2}{c}{ NSPL } & \multicolumn{2}{c}{ NLPL } & \multicolumn{2}{c}{ PSPL (g) } \\
\cline { 2 - 7 } & Lote A & Lote B & Lote A & Lote B & Lote A & Lote B \\
\hline 0 & $127 \mathrm{~b}$ & $136 \mathrm{a}$ & $56 \mathrm{a}$ & $59 \mathrm{a}$ & $26,5 \mathrm{a}$ & $22,4 \mathrm{~b}$ \\
2 & $143 \mathrm{a}$ & $142 \mathrm{a}$ & $57 \mathrm{a}$ & $60 \mathrm{a}$ & $26,6 \mathrm{a}$ & $25,5 \mathrm{a}$ \\
4 & $169 \mathrm{a}$ & $144 \mathrm{~b}$ & $59 \mathrm{a}$ & $61 \mathrm{a}$ & $27,4 \mathrm{~b}$ & $28,9 \mathrm{a}$ \\
6 & $170 \mathrm{a}$ & $130 \mathrm{~b}$ & $59 \mathrm{a}$ & $62 \mathrm{a}$ & $28,4 \mathrm{a}$ & $27,7 \mathrm{a}$ \\
8 & $182 \mathrm{a}$ & $125 \mathrm{~b}$ & $69 \mathrm{a}$ & $57 \mathrm{~b}$ & $31,0 \mathrm{a}$ & $26,5 \mathrm{~b}$ \\
\hline Média & 158 & 135 & 60 & 60 & 28,0 & 26,2 \\
\hline C.V & 4,4 & \multicolumn{2}{c}{5,0} & \multicolumn{2}{c}{3,5} \\
\hline
\end{tabular}

*Médias seguidas pela mesma letra, em cada variável, não diferem entre si pelo teste de Tukey a $5 \%$ de probabilidade.

Na figura 2 é possível observar que o tratamento das sementes de soja com zinco, em geral, proporcionou efeitos positivos em todas as variáveis. O número total de sementes por planta, no Lote A apresentou resposta linear, aumentando 6,9 sementes por planta para cada unidade de aumento da dose (Figura 2A). Já o Lote $B$ o modelo que se ajustou aos dados foi o quadrático com ponto de máxima eficiência na dose de $2,7 \mathrm{~mL} \mathrm{~kg}$ de sementes ${ }^{-1}$.

Para o número total de legumes por planta, o Lote A apresenta aumento de 1,4 legumes por planta para cada unidade de aumento da dose, acarretando na maior dose testada ( $8 \mathrm{~mL} \mathrm{~kg}$ de sementes ${ }^{-1}$ ) um número total de legumes por planta de 66 (Figura 2 B). No entanto, esse efeito não foi observado para o
Lote $B$, onde a mesma não respondeu de forma significativa ao tratamento das sementes.

Em relação ao peso de sementes por planta, o Lote $A$ apresentou um aumento de 0,53 $\mathrm{g}$ por planta para cada unidade de aumento da dose de zinco, resultando num acréscimo de 4,25 g por planta na dose de $8 \mathrm{~mL} \mathrm{~kg}$ de sementes ${ }^{-1}$, em relação a dose zero (Figura $2 \mathrm{C}$ ). Para o Lote $\mathrm{B}$ o ponto de máxima eficiência foi atingido na dose de $5,01 \mathrm{~mL} \mathrm{~kg}$ de sementes ${ }^{-1}$, resultando num peso de $28,4 \mathrm{~g}$ por planta. Estes resultados estão de acordo com os obtidos por Funguetto et al. (2010), os quais verificaram aumentos lineares no número de sementes por panícula e peso de sementes por planta, com doses crescentes de zinco. Da mesma forma, Oliveira (2007) verificou aumento na produção de soja após o tratamento com Acaplus ( $8,5 \%$ de $\mathrm{Zn}+7 \% \mathrm{~N})$. Em contraste, 
Orioli Júnior et al. (2008) não observaram diferença no número de espiguetas de trigo após as sementes terem sido tratadas com zinco. $\mathrm{Da}$ mesma forma, Garcia et al. (2009) não verificaram diferença no número de vagens por planta de soja com a aplicação de zinco e cobre.

Figura 2. Número de sementes por planta (A), número de legumes por planta (B) e peso de sementes por planta $(C)$ oriundas de sementes de soja tratadas com diferentes doses de zinco.
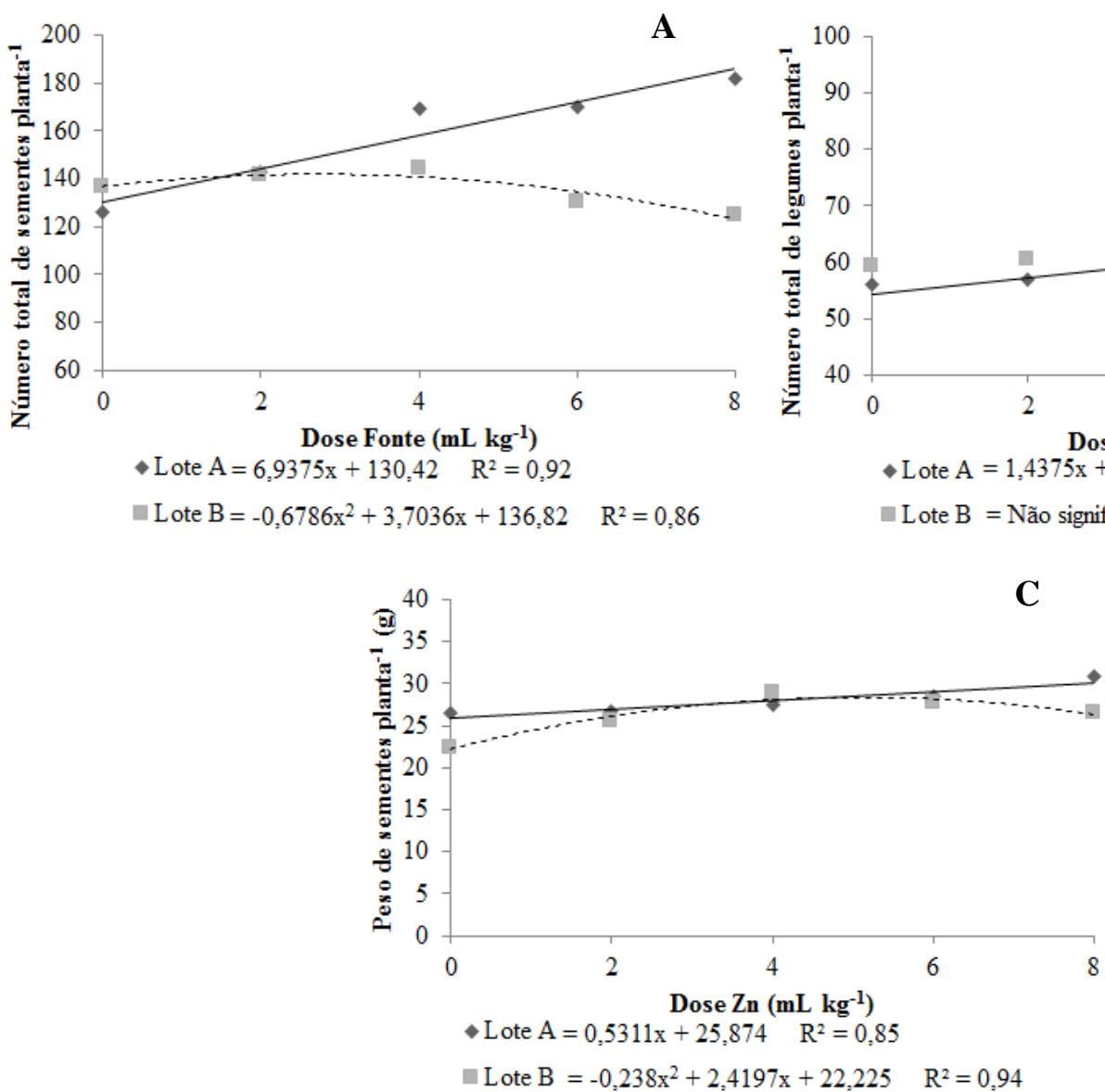

C
Na análise da variância dos dados obtidos para a qualidade fisiológica das sementes produzidas, não foi constatado interação para nenhuma das variáveis analisadas (Tabela 3). 0 zinco é um ativador enzimático e as sementes portadoras de melhor nível de qualidade podem apresentar melhorias no seu desempenho fisiológico, quando enriquecida com zinco (RIBEIRO; SANTOS, 1996), porém de acordo com os resultados obtidos para a qualidade fisiológica das sementes produzidas não foi constatado esse efeito. As variáveis germinação, teste de frio, envelhecimento acelerado e emergência a campo não apresentaram significância na comparação de médias e regressão polinomial, exceto para o envelhecimento acelerado que apresentou efeito ao aumento das doses (Figura $3 \mathrm{~A}$ ). Em trabalho conduzido por Teixeira et al. (2005), também observaram que o zinco não influenciou na qualidade fisiológica das sementes de feijão. Para

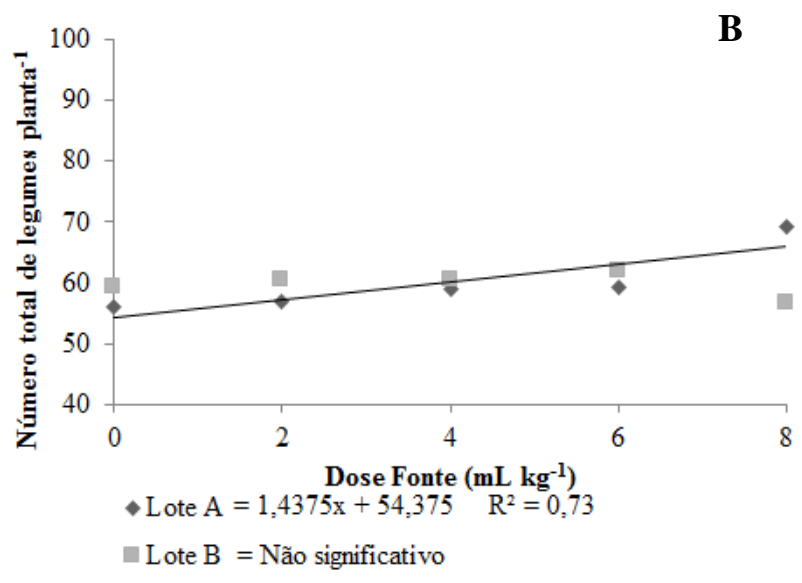

a primeira contagem da germinação, comprimento da parte aérea e de raiz foi observado que para a comparação de médias, 0 Lote $A$ foi superior ao Lote B. Essa diferença de comportamento mostrado pelos lotes pode ser explicada pela possível diferença na eficiência de utilização de nutrientes (OLIVEIRA et al., 2003). No entanto, para Vieira et al. (1994) e Aguero et al. (1997), a qualidade fisiológica das sementes é mais influenciada pelas condições ambientais prevalecentes durante a fase de maturação e colheita do que pelas características da própria cultivar. Oliveira et al. (2014) verificaram que o tratamento de sementes de aveia com os produtos Teprosyn ${ }^{\mathrm{TM}} \mathrm{Zn}$ e Quimifol seed $78^{\circledR}$ podem ser utilizados nas doses de 100 e $200 \mathrm{~mL}$ $100 \mathrm{~kg}^{-1}$ de sementes, respectivamente, sem prejudicar a qualidade fisiológica das sementes. 
Tabela 3. Primeira contagem da germinação (PCG), comprimento da parte aérea (CPA) e de raiz (CR) de plântulas oriundas de sementes de soja produzidas em função do tratamento com diferentes doses de zinco.

\begin{tabular}{|c|c|c|c|c|c|c|}
\hline \multirow{2}{*}{$\begin{array}{c}\text { Dose } \\
\left(\mathrm{mL} \mathrm{kg} \text { de sementes }{ }^{-1}\right)\end{array}$} & \multicolumn{2}{|c|}{ PCG (\%) } & \multicolumn{2}{|c|}{$\mathrm{CPA}(\mathrm{cm})$} & \multicolumn{2}{|c|}{$\mathrm{CR}(\mathrm{cm})$} \\
\hline & Lote A & Lote B & Lote A & Lote B & Lote A & Lote B \\
\hline 0 & 96 & 93 & 9,6 & 7,2 & 15,2 & 12,1 \\
\hline 2 & 95 & 91 & 8,5 & 6,1 & 14,5 & 11,9 \\
\hline 4 & 94 & 91 & 8,2 & 6,2 & 13,9 & 12,4 \\
\hline 6 & 96 & 93 & 8,1 & 6,2 & 14,2 & 12,1 \\
\hline 8 & 95 & 93 & 7,9 & 6,1 & 14,4 & 12,3 \\
\hline Média & $95 a$ & $92 \mathrm{~b}$ & $8,4 \mathrm{a}$ & $6,4 \mathrm{~b}$ & $14,4 \mathrm{a}$ & $12,2 b$ \\
\hline C.V & \multicolumn{2}{|c|}{2,1} & \multicolumn{2}{|c|}{4,7} & \multicolumn{2}{|c|}{4,9} \\
\hline
\end{tabular}

*Médias seguidas pela mesma letra, em cada variável, não diferem entre si pelo teste de Tukey a 5\% de probabilidade.

Figura 3. Envelhecimento acelerado e comprimento da parte aérea de plântulas oriundas de sementes de soja tratadas com diferentes doses de zinco.
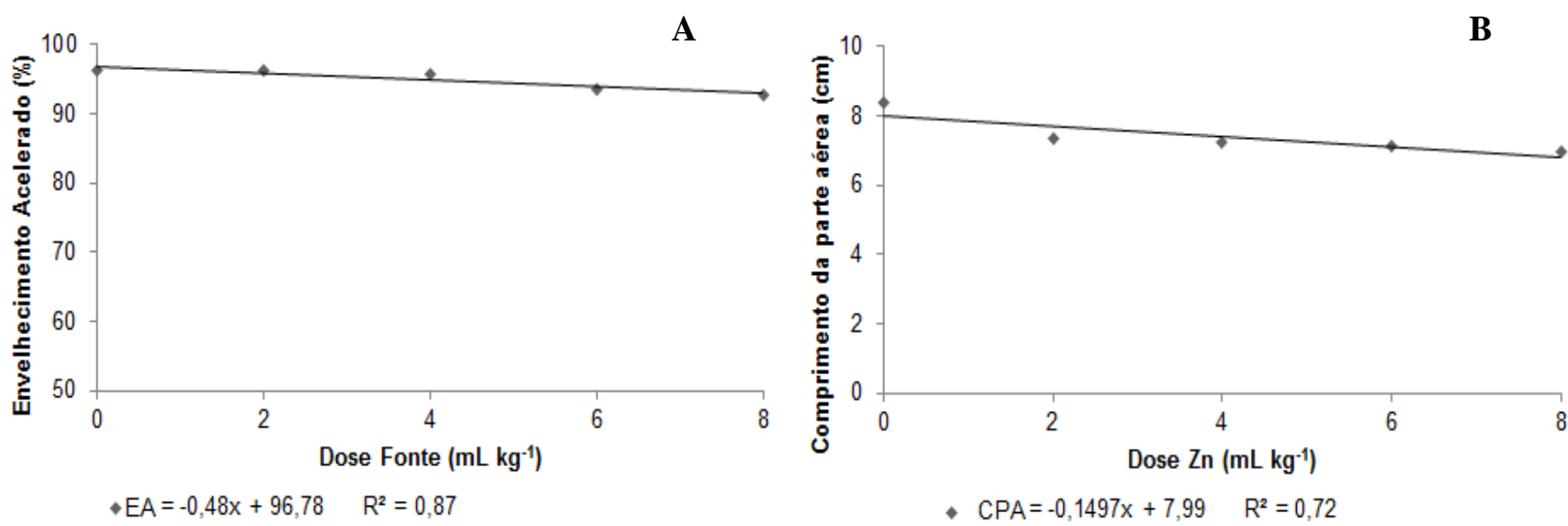

Quanto ao efeito das doses de zinco, para a média dois lotes no envelhecimento acelerado e comprimento da parte aérea (Figura 3 A e 3 B), o modelo que se ajustou em ambas variáveis foi o linear decrescente, sendo observado que há uma redução de 0,48 pontos percentuais e de $0,15 \mathrm{~cm}$ para cada unidade de aumento da dose, respectivamente.

De modo geral, observa-se que os resultados de estudos com tratamento de sementes, relacionados com micronutrientes tem mostrado muitas variações na sua utilização. No entanto, o efeito positivo na qualidade fisiológica das sementes tratadas e nas características agronômicas, pode ser atribuído ao tratamento das sementes de soja com zinco. Nas características agronômicas, os resultados obtidos podem ter sido ocasionados pelo fato da planta estar bem nutrida na fase reprodutiva, o que pode favorecer a diminuição do abortamento de sementes, ou seja, quanto melhor seu

equilíbrio nutricional maior será a capacidade da planta em manter maior número de sementes, o que, consequentemente pode influenciar no peso de sementes (LOPES, 1999).

\section{CONCLUSÕES}

O tratamento das sementes de soja nas doses entre 2 a $6 \mathrm{~mL} \mathrm{~kg}$ de sementes $^{-1}$ apresentou os melhores resultados para a qualidade fisiológica e componentes do rendimento.

O número de sementes por planta, número de legumes por planta e peso de sementes por planta apresentam incrementos com o aumento das doses de zinco.

O tratamento das sementes de soja com zinco não influencia a qualidade fisiológica das sementes produzidas.

Os lotes apresentam comportamentos diferentes em resposta ao tratamento das sementes com zinco. 


\section{REFERÊNCIAS}

AGUERO, J. A. P.; VIEIRA, R. D.; BITTENCOURT, S. R. M. Avaliação da qualidade fisiológica de sementes de cultivares de soja. Revista Brasileira de Sementes, v. 19, n. 2, p.254-259, 1997. https://doi.org/10.17801/0101-

\section{2/rbs.v19n2p254-259}

ALLOWAY, B. J. Zinc in soils and crop nutrition. Paris: Internacional Fertilizer Industry Associattion, 2008, 133 p.

ASSIS, M. O.; RODRIGUES, B. R. A.; DAVID, A. M. S. S.; CANGUSSÚ, L. V. S.; MOTA, W. F. Potencial fisiológico de sementes de coentro e resposta ao tratamento com fertilizante à base de zinco e molibdênio. Horticultura Brasileira, v.30, n.2, p.7867-7874, 2012.

BERGMANN, W. Colour atlas nutritional disorders of plants. New York: Phosyn, 1992. $386 p$.

BONNECARRÉRE, R. A. G.; LONDERO, F. A. A.; SANTOS, O.; SCHMIDT, D.; PILAU, F. G.; MANFRON, P. A.; DOURADO NETO, D. Resposta de genótipos de arroz irrigado à aplicação de zinco. Revista Faculdade Zootecnia Veterinária e Agronomia de Uruguaiana, v. 10 , n. 1, p. 109116, 2003.

BRASIL. Ministério da Agricultura, Pecuária e Abastecimento. Regras para análise de sementes. Brasília: Mapa/ACS, 2009. 399 p.

CARVALHO, N.M.; NAKAGAWA, J. Sementes: ciência, tecnologia e produção. 4. ed. Jaboticabal: Funep, 2000. 588p.

CÍCERO, S. M.; VIEIRA, R. D. Teste de frio. In: VIEIRA, R.D.; CARVALHO, N.M. (Eds.) Testes de vigor em sementes. Jaboticabal: FUNEP, 1994. p.151-164.

COMISSÃO DE QUÍMICA E FERTILIDADE DO SOLO - RS/SC. Manual de calagem e adubação para os estados do Rio Grande do Sul e de Santa Catarina. 11. ed. Porto Alegre: NRS/SBCS, 2016. $376 p$.

CONAB. Acompanhamento da Safra Brasileira de Grãos 2016/2017. Brasília: Conab, 2017. (Oitavo Levantamento, v.4, maio 2017)
EPSTEIN, E.; BLOOM, A. J. Mineral nutrition of plants: principles and perspectives. 2. ed. Sunderland: Sinauer Associates, 2004. 400p.

FUNGUETTO, C. I.; PINTO, J. F.; BAUDET, L.; PESKE, S. T. Desempenho de sementes de arroz irrigado recobertas com zinco. Revista Brasileira de Sementes, v. 32, n. 2. p. 117-115. 2010. https://doi.org/10.1590/S0101$\underline{31222010000200014}$

FURLANI, A. M. C.; FURLANI, P. R. Resposta de cultivares de milho a zinco em solução nutritiva. Bragantia, v. 55, n. 2, p. 365-369, 1996. https://doi.org/10.1590/S0006$\underline{87051996000200023}$

FURLANI, A. M. C.; FURLANI, P. R.; MEDA, A. R.; DUARTE, A. P.; Efficiency of maize cultivars for zinc uptake and use. Scientia Agricola, v.62, n.3, p.264-273, 2005. https://doi.org/10.1590/S0103$\underline{90162005000300010}$

GARCIA, G. G.; SILVA, T. R. B.; SECCO, D. Épocas de aplicação e doses de fertilizantes a base de cobre e zinco no rendimento de grãos de soja. Cultivando o Saber, v.2, n.4, p.18-25, 2009.

LONGNECKER, N. E.; ROBSON, A. D. Distribution and transport of zinc. In: Zinc in soils and plants. Dordrecht: Kluwer Academic Publishers, 1993. p. 79-91. https://doi.org/10.1007/978-94-011-0878$\underline{26}$

LOPES, A.S. Micronutrientes: filosofias de aplicação e eficiência agronômica. São Paulo. ANDA, 1999. 72p. (Boletim Técnico, 8).

MACHADO, A. A.; CONCEIÇÃO, A. R. Sistema de análise estatística para Windows. WinStat. Versão 1.0. UFPel, 2003.

MALAVOLTA, E. Manual de nutrição mineral de plantas. São Paulo: Editora Agronômica Ceres, 2006, 638p.

MARCOS FILHO, J. Fisiologia de sementes de plantas cultivadas. Piracicaba: FEALQ, 2005. 495 p.

MARSCHNER, P. Mineral nutrition of higher plants. 3. ed. Oxford: Elsevier, 2012. 643p. 
NAKAGAWA, J. Testes de vigor baseados no desempenho das plântulas. In: KRZYZANOWSKI, F. C.; VIEIRA, R. D.; FRANÇA-NETO, J. B. Vigor de sementes: conceitos e testes. Londrina: ABRATES, Cap. 2, p. 9-13. 1999.

NUNES, J.C. Tratamento de semente - qualidade e fatores que podem afetar a sua performance em laboratório. Londrina: Syngenta Proteção de Cultivos, 2005. 16p.

OLIVEIRA, E. F. Resposta do milho ao Awaken e da soja ao Acaplus aplicados via sementes. Relatório de pesquisa. Cascavel: Coodetec, 2007.

OLIVEIRA, R. H.; SOUZA, M. J. L.; MORAIS, O. M.; GUIMARÃES, B. V. C.; PEREIRA JÚNIOR, H. A. Potencial fisiológico de sementes de mamona tratadas com micronutrientes. Acta Scientiarum Agronomy, v. 22, n. 4, p.701-707, 2010. https://doi.org/10.4025/actasciagron.v32i4.4829

OLIVEIRA, S. C.; COSTA, M. C. G.; CHAGAS, R. C. S.; FENILLI, T. A. B.; HEINRICHS, R.; CABRAL, C. P.; MALAVOLTA, E. Resposta de duas cultivares de arroz a doses de zinco aplicado como oxissulfato. Pesquisa Agropecuária Brasileira, v. 38, n. 3, p. 387-396, 2003. https://doi.org/10.1590/S0100$\underline{204 \times 2003000300008}$

OLIVEIRA, S.; TAVARES, L. C.; LEMES, E. S.; BRUNES, A. P.; DIAS, I. L; MENEGHELLO, G. E. Tratamento de sementes de Avena sativa L. com zinco: qualidade fisiológica e desempenho inicial de plantas. Semina: Ciências Agrárias, v. 35, n.3, p. 1131-1142, 2014. https://doi.org/10.5433/1679$\underline{0359.2014 v 35 n 3 p 1131}$

ORIOLI JUNIOR, V.; MELLO, P. R.; LEONEL, L. C. CAZETTA, D. A.; SILVEIRA, C. M.; QUEIROZ, R. J. B.; GAMA, B. J. C. H. A. Modos de aplicação de zinco na nutrição e na produção de massa seca de plantas de trigo. Revista de la Ciencia del Suelo y Nutrición Vegetal, v. 8, n. 1, p. 28-36, 2008.

RIBEIRO, N. D.; SANTOS, O. S. Aproveitamento do zinco na semente na nutrição da planta. Ciência Rural, v. 26, n. 1, p. 159-165,1996. https://doi.org/10.1590/S0103$\underline{84781996000100030}$

SINGH, M. V. Micronutrient seed treatment to nourish the crops at the critical stages of growth.
Indian Institute of Soil Science Technology Bulletin, v.19, n.1, p.1-93, 2007.

STRECK, E. V.; KÄMPF, N.; DALMOLIN, R. S. D.; KLAMT, E., NASCIMENTO, P.C.; SCHNEIDER, P.; GIASSON, E. PINTO, L.F.S. Solos do Rio Grande do Sul. 2. ed. Porto Alegre, EMATER/RSASCAR, 2008. p. 222.

TAVARES, L. C.; BRUNES, A. P.; TUNES, L. M.; GADOTTI, G. I.; BARROS, A,C.S.A. ; VILLELA, F. A. The yield and physiological quality of oat seeds subjected to cover with zinc. Acta Scientiarum, v. 35, n.3, p. 357-361, 2013.

TEIXEIRA, I.R.; BORÉM, A.; ARAÚJO, G.A.A.; ANDRADE, M.J.B. Teores de nutrientes e qualidade fisiológica de sementes de feijão em resposta à adubação foliar com manganês e zinco. Bragantia, v.64, n.1, p.83-88, 2005. https://doi.org/10.1590/S0006$\underline{87052005000100009}$

TUNES, L. M.; PEDROSO, D. C.; TAVARES, L. C.; BARBIERI, A. P. P.; BARROS, A. C. S. A.; MUNIZ, M. F. B. Tratamento de sementes de trigo com zinco: armazenabilidade, componentes do rendimento e teor do elemento nas sementes. Ciência Rural, v. 42, n. 7, p. 1141-1146, 2012. https://doi.org/10.1590/S010384782012000700001

USDA. United States Department of agriculture. Disponível em: www.fas.usda.gov. Acesso em: 22 junho de 2017.

VIEIRA, R. D.; CARVALHO, N. M.; SADER, R. Testes de vigor e suas possibilidades de uso. In: VIEIRA, R. D.; CARVALHO, N. M. (eds.) Testes de vigor em sementes. Jaboticabal: FUNEP, 1994. p.31-47.

YAGI, R.; SIMILI, F. F.; ARAÚJO, J. C.; PRADO, R. M.; SANCHEZ, S. V.; RIBEIRO, C. E. R.; BARRETTO, V. C. M. Aplicação de zinco via sementes e seu efeito na germinação, nutrição e desenvolvimento inicial do sorgo. Pesquisa Agropecuária Brasileira, v.41, n.4, p.655-660, $2006 . \quad$ https://doi.org/10.1590/S0100$\underline{204 \times 2006000400016}$

Recebido para publicação em 02/06/2017

Revisado em 04/09/2017

Aceito em 11/09/2017 